\author{
Jan Sińczak ${ }^{* *}$, Maciej Pietrzyk*, Piotr Skubisz ${ }^{* * * *}$, Aneta Lukaszek-Sołek ${ }^{* * *}$
}

\title{
MODELLING OF MICROSTRUCTURE DEVELOPMENT IN FORGING OF A WINDMILL SHAFT
}

\section{INTRODUCTION}

Large forgings, such as windmill main shafts, are usually manufactured in processes of open-die forging, involving operations of compression between flat dies and cogging both in flat and shaped dies. On account of large dimensions, such parts are forged from cast ingots, ranging from a several to dozens of tons, which are subjected to preliminary forging operations in the route of upsetting and cogging sequences. The aim is to break down cast structure and provide proper mechanical properties. Forming windmill shafts is thus accompanied by fracture related problems resulting from forging brittle cast ingots, gradients of temperature, non-uniformity of deformation resulting from large dimensions, which make this process very complex from technological point of view.

Typical technology of forging of such part consists of preliminary forging of an ingot aimed at removing the scarf, followed by cogging operations to obtain required diameters and final forming of the part into desired dimensions and shape (Fig. 1), including forming of a flange in the open die forging operation. Because of limited capacity of a forging press, reduction of the cross section in stretch forming operations is achieved in two stages: reduction to intermediate diameter of $1050 \mathrm{~mm}$, and required final diameters. Each operation of cogging consists of several passes [1]. For example, reduction of the cross-section into diameter of $1050 \mathrm{~mm}$ carried out in cogging process, shown in Figure 1 involves six passes (Fig. 2), each consisting of several bites, followed by over a dozen smoothing drafts. During the forging process, the intermediate reheating is carried out twice, after reduction of diameter to $1050 \mathrm{~mm}$ and after reduction to $580 \mathrm{~mm}$, before upsetting of the flange. Because of extremely high values of forging load, the upsetting operation itself (Fig. 3), consists of approximately ten drafts [2].

* Prof, ${ }^{* * P h . D ., ~ D . S c ., ~} * * * P h . D .$, ****M.Sc.: Faculty of Metals Engineering and Industrial Computer Science, AGH University of Science and Technology, Cracow, Poland; sinczak@metal.agh.edu.pl 


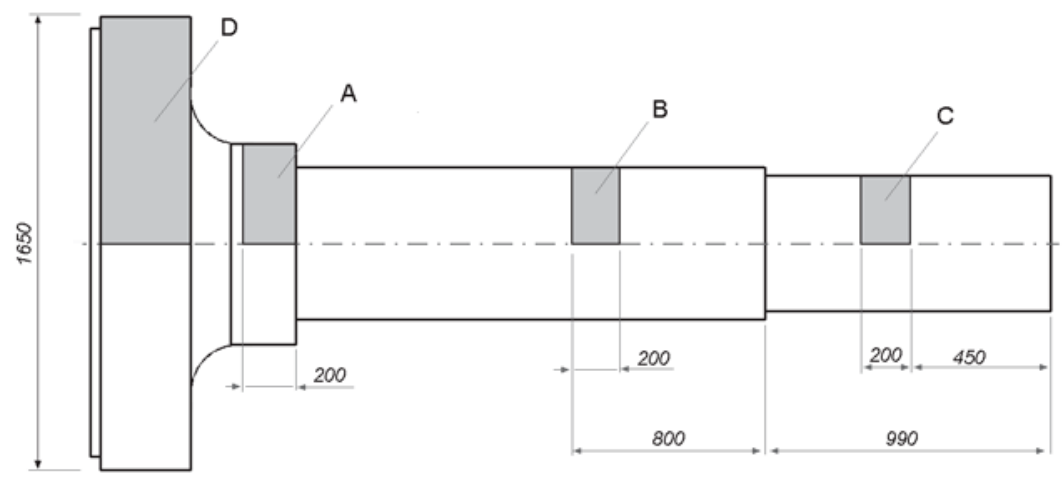

Fig. 1. Shape and dimensions of the forging of a shaft, with localization of analysed cross-sections

a)

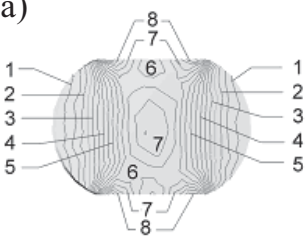

$-0.04$

$2-0.08$
$3-0.12$

$4-0.16$

$5-0.2$

$5-0.2$
$6-0.26$

$6-0.26$
$7-0.3$

$\begin{array}{ll}7 & =0.3 \\ 8 & -0.34\end{array}$

b)

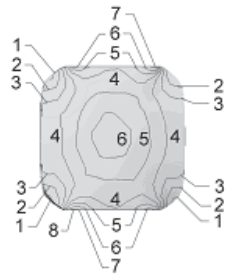

e)

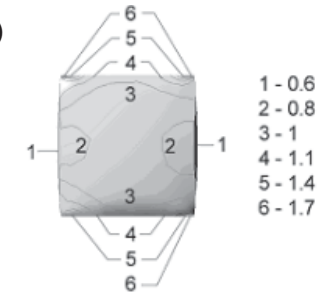

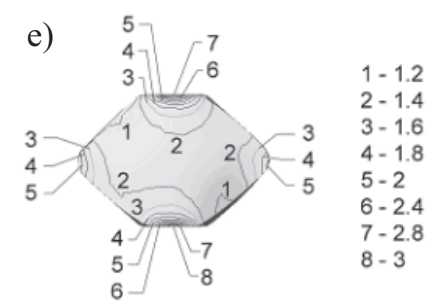

c)
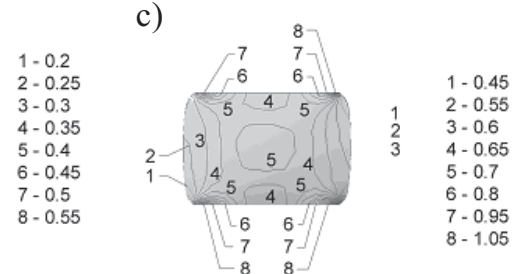

f)

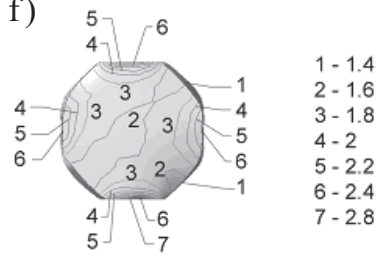

Fig. 2. Effective strain distribution in consecutive bites of cogging operation: a) initial bite; b) after $90^{\circ}$ rotation; c) after $90^{\circ}$ rotation; d) after $90^{\circ}$ rotation; e) after $45^{\circ}$ rotation; $f$ ) after $45^{\circ}$ rotation

a)

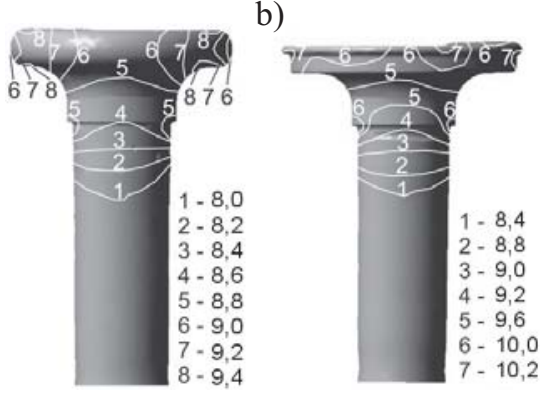

Fig. 3. Effective strain distribution in the first (a) and the second stage (b) of upsetting operation
The above described complexity of the forging process of large forgings, such as windmill shafts, results in a few interacting and overlapping thermodynamic and microstructural processes occurring during the whole cycle of forging process, which have an effect on the properties of material during deformation, especially, fracture related problems, and on final properties of the forged part. Since the considered forgings are subjected to further heat treatment, the latter aspect is less important. 
Large dimensions of the forging cause inevitable inhomogeneities of strains (Fig. 2 and Fig. 3). Differences in diameter of particular sections are the source of significant variations in material conditions, resulting from different history of deformation. Sections of diameter reduced to $580 \mathrm{~mm}$ in cogging operations are characterized by a larger amount of plastic work. Smaller diameter, and thereby, faster cooling of the material in connection with shorter time of action of high temperature results in smaller tendency to grain growth in that section of a forging. Temperature gradients with simultaneous nonuniformity of deformation in the cross-section bring about non-uniform recovery and recrystallization processes, which results in non-uniform microstructure resulting in material behaviour in different sections of the shaft.

Estimation of the changes that occur in microstructure of the shaft in following stages of forging enable to provide appropriate process parameters, and better control of the material condition in subsequent stages of forming of the part, in the result. Analysis of factors that influence the changes in microstructure allows optimisation of process conditions, reduction of the number of drop-outs, as well as improvement of the quality and homogeneity of material before heat treatment. However, dimensions of the analysed part, make it difficult to study the microstructural changes by means of destructive methods. Because of above-mentioned non-uniformities resulting from large gradients of deformation and temperature, large number of specimens, taken out after consecutive stages of the process, would be necessary. Thus, modelling of changes in microstructure during forging process is one of the most convenient methods of investigation of the size of recrystallized grains and/ or grain growth during particular stage of deformation to predict an influence of forging process parameters on the material behaviour during deformation.

\section{NUMERICAL MODELLING OF STRAIN DISTRIBUTION COGGING AND UPSETTING OPERATIONS}

Numerical modelling of cogging and upsetting operations was carried out with a commercial code QForm 3D in three-dimensional state of strain. Calculations were performed for the current forging technology, temperature regime and values of reductions derived from industrial practice. In accordance with process parameters determined in the forging plant CELSA, initial temperature of forging $1200^{\circ} \mathrm{C}$, tool temperature $300^{\circ} \mathrm{C}$, upper die velocity $10 \mathrm{~mm} / \mathrm{s}$ and friction factor 0,4 were assumed. The calculations were performed as a multioperational sequence of forging operations, with maintained history of deformation. The example of results of mechanical calculations are presented in Figures 2 and 3. More detailed results can be found in [1]. Effective strain distributions in consecutive drafts of cogging (Fig. 2) and upsetting (Fig. 3) operations, were basis for further calculations of microstructural changes.

\section{MODELLING OF MICROSTRUCTURE EVOLUTION DURING FORGING}

The microstructure after forging is resultant not only from appriopriately determined geometry parameters of upsetting and cogging operations. Due to intermediate reheating and further reduction of diameter at the end of the shaft, previously formed sections are 
subjected to long-lasting effect of high temperature. Since sustained dwelling time at high temperature is longer than the time needed for recrystallization to proceed, grain growth process occurs. Such a situation takes place in a forging cycle of the analysed shaft, which gives no information as for material condition after individual forging stages. Actual influence of the forging process variables upon the microstructure can be derived from the modelling of microstructure evolution during the whole forging cycle.

Formulation of the model of microstructure evolution in steel undergoing thermomechanical processing involves determination of changes in microstructure, induced by plastic strain. Formulas which describe and allow calculations of kinetics of these phenomena, as well as the state of the material affected by the microstructural changes (for example, grain size), are applied in the model.

The concept of the model is based on the fundamental works of Sellars, who proposed the methodology and basic equations describing microstructure evolution during thermomechanical processing of steels [3, 4]. Calculations of austenite grain size after recrystallization were based on formula proposed by Sellars and Whiteman [5]

$$
D_{r}=25\left(14.925 \frac{10^{-9} Z}{8.5}\right)^{-0.67} \frac{D_{0}^{0.5}}{\varepsilon}
$$

where:

$D_{r}$ - size of recrystalized grain,

$Z$ - Zener-Hollomon parameter,

$D_{0}$ - initial grain size, prior to deformation,

$\varepsilon-$ strain.

The kinetics of static recrystallization was modeled by the Johnson-Mehl-AvramiKolmogorov equation. The recrystallized volume fraction $X$ in this equation is expressed as a function of the holding time after deformation

$$
X=1-\exp \left[0.693\left(\frac{t}{t_{50}}\right)^{k}\right]
$$

where:

$t$ - holding time,

$t_{50}$ - time for $50 \%$ recrystallization,

$k$ - Avrami exponent.

The most commonly used form of equation describing time for $50 \%$ recrystallization $\left(t_{50}\right)$, is

$$
t_{50}=A \varepsilon^{p} D_{0}^{q} \exp \left(\frac{Q_{R X}}{R T}\right)
$$


where:

$$
\begin{aligned}
\dot{\varepsilon} & - \text { strain rate, } \\
Q_{R X} & - \text { apparent activation energy for recrystallization, } \\
R & - \text { gas constant, } \\
T & - \text { absolute temperature. }
\end{aligned}
$$

According to Sellars, the following values of coefficients in equation (4) were assumed for the investigated steel: $A=2.5 \cdot 10^{-19}, p=-4, q=2, Q_{R X}=300000 \mathrm{~J} / \mathrm{mol}, k=1.7$. The formulae (1)-(3) are valid for a wide range of chemical compositions of carbon-manganese steels, which are microalloyed with below $0.01 \% \mathrm{Nb}$ and $\mathrm{V}$.

For analysed chemistry of steel: $0.34 \% \mathrm{C}, 0.66 \% \mathrm{Mn}, 0.23 \% \mathrm{Si}, 0.26 \% \mathrm{Mo}, 1.55 \% \mathrm{Ni}$, $0.005 \% \mathrm{Ti}, 0.006 \% \mathrm{~V}, 0.006 \% \mathrm{Nb}, 0.13 \% \mathrm{Cu}, 1.57 \% \mathrm{Cr}$, the grain growth parallel to forging operations is described by the following equation

$$
D^{n}=D_{r}^{n}+k t \exp \left(\frac{-Q_{q}}{R T}\right)
$$

Hodgson and Gibbs [6], for carbon-manganese steels containing small amount of vanadium, suggested the following values of coefficients: $n=7 ; k=1.45 \cdot 10^{27} ; Q_{d}=400000 \mathrm{~J} / \mathrm{mol}$. The formula (4) takes into account slowing down the grain growth by alloying elements.

Calculations and the analysis of the microstructure were performed for all characteristic sections of forging of a shaft, namely, stretch-formed sections of diameters 670, 610 and $580 \mathrm{~mm}$, and a flange of $1650 \mathrm{~mm}$ diameter (respectively, sections A, B, C and D in Fig. 1), at three depths under the surface: right under the surface, at a half of the radius and in the axis of the shaft. Initial austenite grain size $50 \mu \mathrm{m}$, deformation 0.25 , strain rate $2 \mathrm{~s}^{-1}$ and initial temperature $1000^{\circ} \mathrm{C}$ was assumed.

Temperature changes during forging cycle versus time are plotted for the investigated cross-sections, as well as, the calculated changes of grain size plotted versus time, are shown in Figures 4-7.
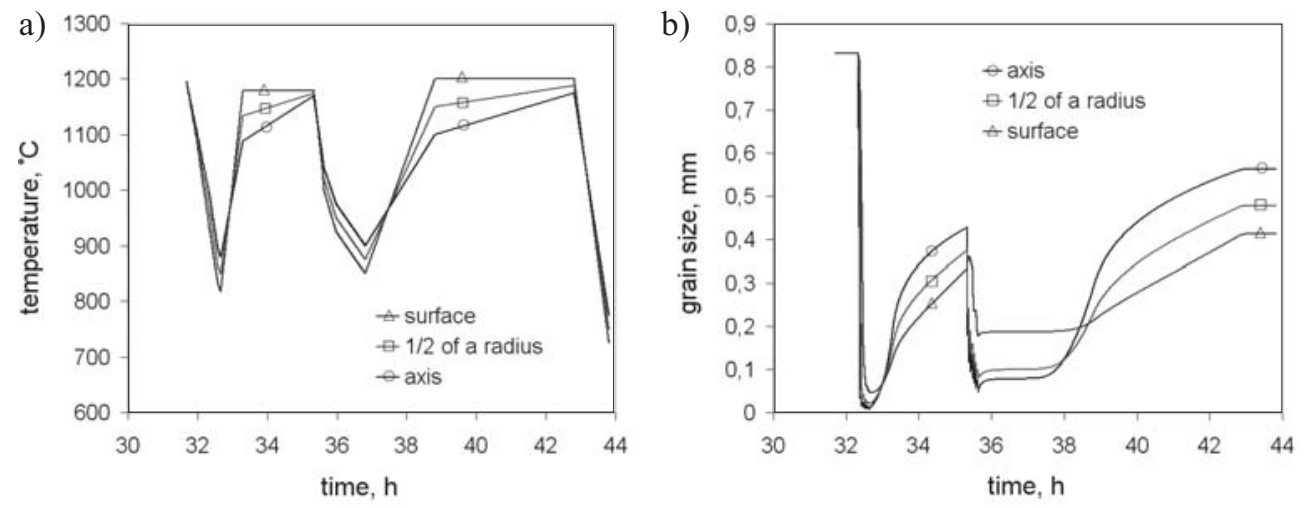

Fig. 4. Calculated plots of: a) temperature; b) grain size changes during forging for diameter $900 \mathrm{~mm}$ 

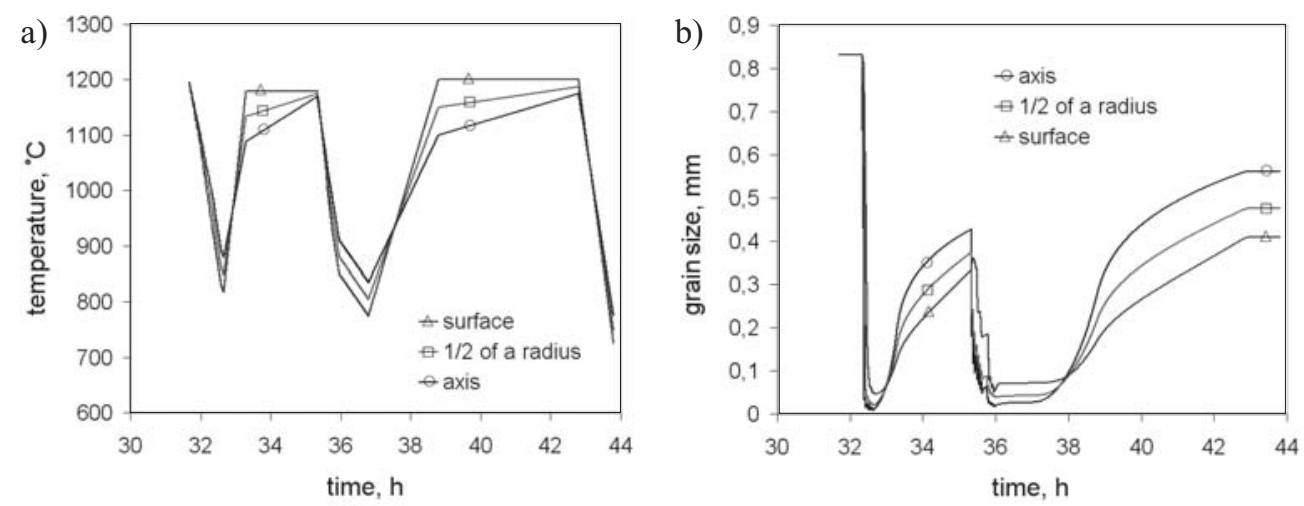

Fig. 5. Calculated plots of: a) temperature; b) grain size changes during forging for diameter $690 \mathrm{~mm}$
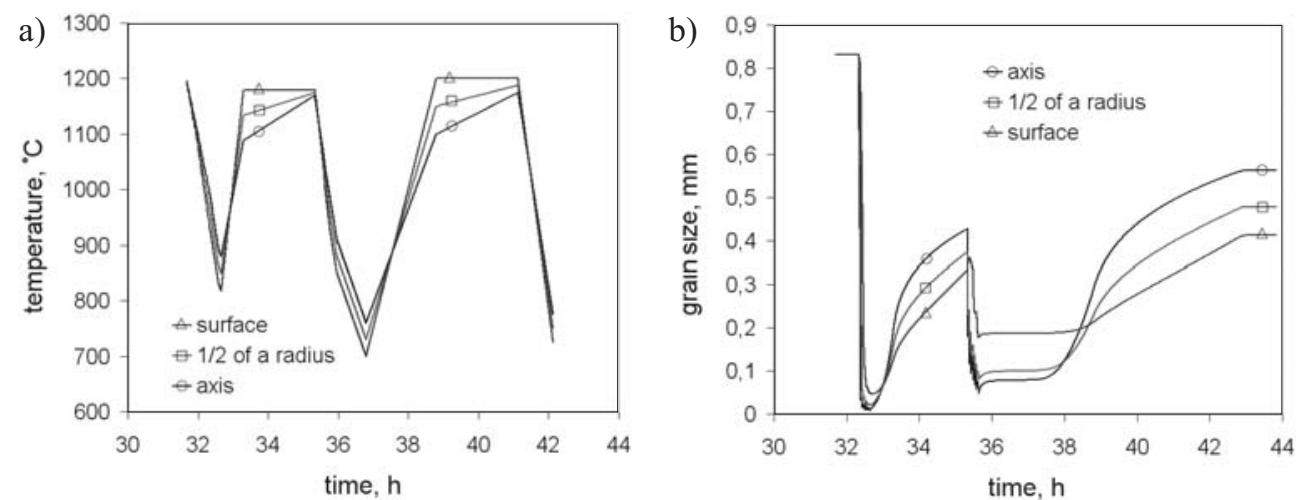

Fig. 6. Calculated plots of: a) temperature; b) grain size changes during forging for diameter $630 \mathrm{~mm}$
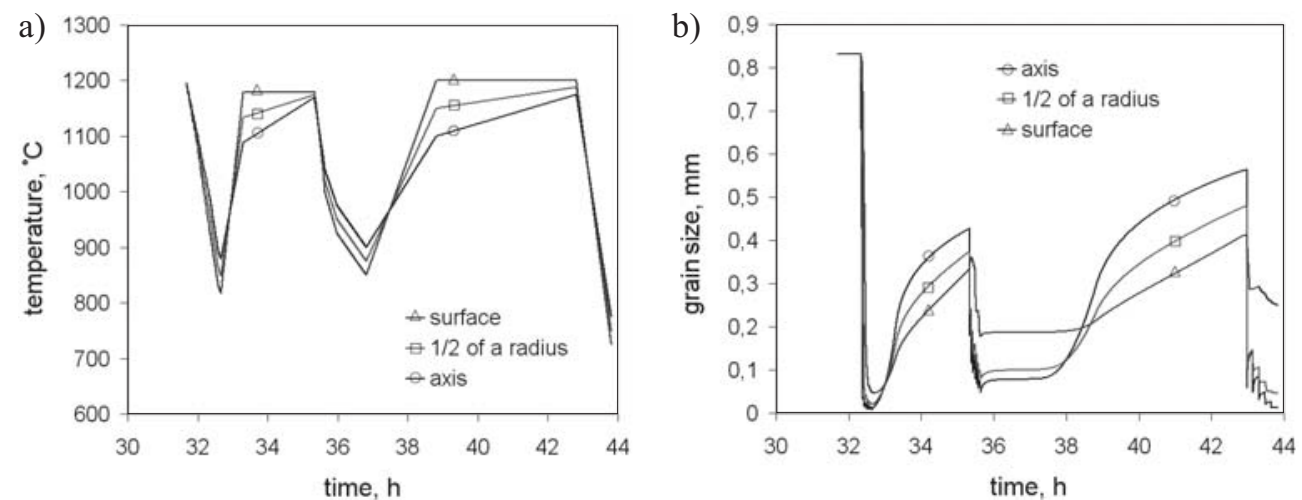

Fig. 7. Calculated plots of: a) temperature; b) grain size changes during forging for diameter $1650 \mathrm{~mm}$ 
To verify the estimation, metallographic work was carried out, to reveal former austenite grains. The specimens were taken out from forgings made of five different heats, at the depth of one third radius. Microstructure representative of obtain results is shown in Figure 8.

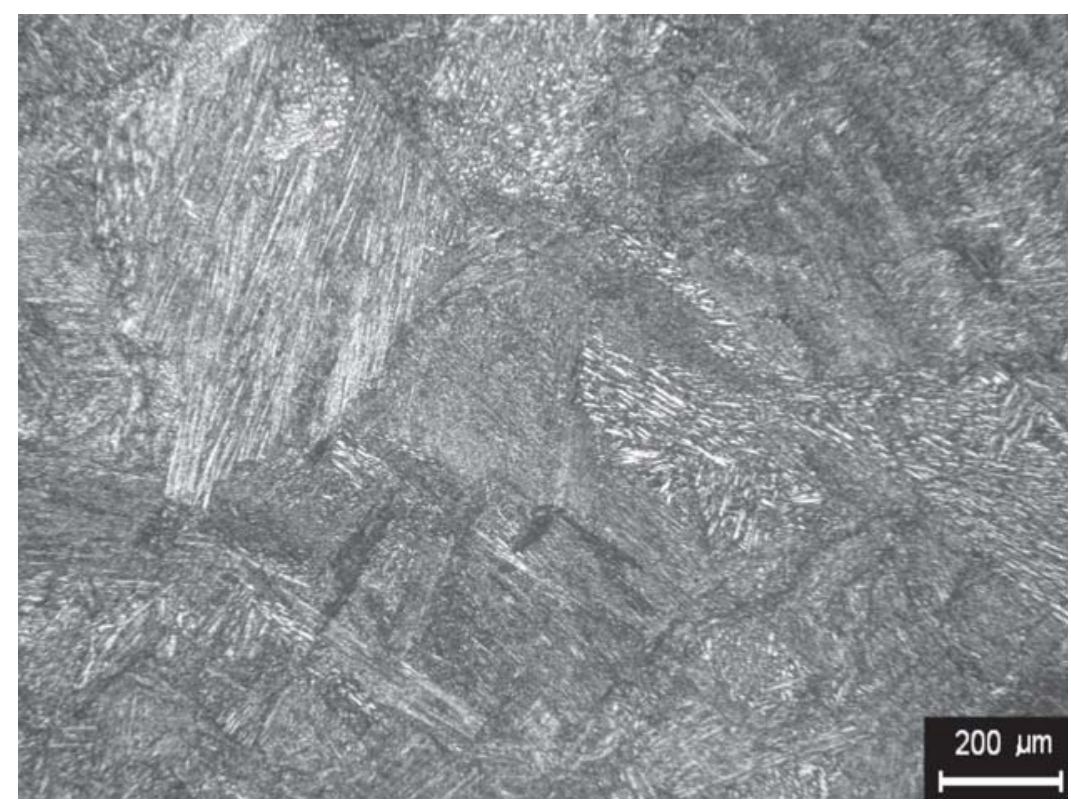

Fig. 8. Microstructure of the forged shaft at the depth of one third of a radius

\section{ANALYSIS OF THE RESULTS}

As indicated by the analysis of microstructure of the deformed metal during forging a windmill main shaft, forging conditions brought about interaction of overlapping processes, resulting in continuous changes in microstructure. The simulation of microstructure evolution illustrates the changes undergoing in the metallurgical structure of the material caused by these processes. As shown in the plots of changes of the grain size during particular stages (Fig. 4-7), after cogging to diameter $1050 \mathrm{~mm}$, in all areas the grain was refined to the size reaching a dozen micrometers in the surface of the forging. Subsequent reheating caused grain growth to about $300 \div 400 \mu \mathrm{m}$. After drawing out to $670 \mathrm{~mm}$ diameter mean size of grains was reduced to about $200 \mu \mathrm{m}$, undergoing further refinement to $15 \div 35 \mu \mathrm{m}$ in sections forged to $610 \mathrm{~mm}$ and $580 \mathrm{~mm}$ diameter. During the second reheating, prior to upset-forging operation, full recrystallization took place and grain growth to about $400 \mu \mathrm{m}$, which was reduced in area of flange to reach about $30 \mu \mathrm{m}$ after forging.

Comparison of microstructure analysis performed for the depth of one third of radius with the results of modelling for the depth of half a radius, show that grain size is slightly overestimated. However coarser grain should be expected for half a radius, the grain size for one the depth of $105 \mathrm{~mm}$ constitutes about a half of relieves area, whereas the rest is 
covered by grains smaller by about $50 \div 100 \mu \mathrm{m}$ than estimated (Fig. 8). It should be noted that in the investigated technology, the examined end, and thereby examined specimens, were formed from thin end of an ingot, which may be of great significance. Nevertheless, the presented modelling is a successful effort to determine guidelines for controlling timetemperature regime and magnitude of draft during open die hot forging operations of heavy forgings of sound microstructure and reliable performance.

\section{CONCLUSIONS}

The presented work shows the results of application of microstructure modelling for forging operations of large sections. Estimation of the effect of the forging process variables on the condition of the material. Prediction of grain size after forging can help determine appropriate temperature, time and amount of deformation in forging operations, allow foreseen condition of the deformed material for assumed variables of the process and, in result, prevent from eventual fractures and/or other metal flow defects.

The results of the modelling of microstructure evolution in the steel of a forged windmill shaft show insufficient amount of deformation in the axis as to obtain homogenous microstructure, which, in combination with defects in metallurgical structure of cast ingot, may be the root of formation of hard-to-detect defects during cogging. Larger amount of strain in the surface areas in connection with faster cooling result in more significant grain refinement, and so, in these areas, higher strength can be expected. As for grain size variations in the length of the shaft, it can be concluded, the differences in strain degrees between particular sections at temperatures above $800^{\circ} \mathrm{C}$, which was estimated to occur in all sections during forging, do not produce significant difference in obtained grain size.

Financial assistance of MNiI (No. AGH 16.16.110.457) is acknowledged.

\section{REFERENCES}

[1] SińczakJ., Łukaszek-Solek A., Skubisz P.: Numerical Modelling of Ingot Stretch Forming in Flat Dies. Hutnik - Wiadomości Hutnicze, 71 (2004) 10, 504-509

[2] Sińczak J., Łukaszek-Sołek A., Bednarek S.: Spęczanie segmentowe kołnierzy dużych wałów. [Segmental upsetting of big haft flance]. Hutnik - Wiadomości Hutnicze (2005) 10, 500-504

[3] Sellars C.M.: Modelling Microstructural Development During Hot Rolling. Mat. Sci. Techn., 6 (1990), 10721081

[4] Sellars C.M.: Physical Metallurgy of Hot Working. Hot Working and Forming Processes, Sellars C.M., Davies G.J. (eds), The Metals Soc., London, 1979, 3-15

[5] Sellars, C.M.: Whiteman, J.A., Recrystallization and Grain Growth in Hot Rolling, Met. Sci., 13 (1979), 187194

[6] Hodgson P.D., Gibbs R.K.: A Mathematical Model to Predict the Mechanical Properties of Hot Rolled C-Mn and Microalloyed Steels. ISIJ Int., 32 (1992), 1329-1338

Received

October 2005 